\title{
7. What are species and why does it matter? Anopheline taxonomy and the transmission of malaria
}

\author{
Robert Attenborough
}

\section{Introduction}

By the mid-twentieth century, taxonomy had, like many things Victorian, become unfashionable. When Washburn (1951: 298) argued for a 'new physical anthropology', he described the discipline's dominant approach of that period as 'static, with emphasis on classification based on types', though he did qualify that characterisation as 'oversimplified'. The change he wanted to encourage was one of emphasis, bringing genetics in without totally rejecting systematics. Even so, it must have seemed to many readers that a viewpoint centred on taxonomy would be allied, not to the new, but to the 'old physical anthropology' (see also Fuentes, 2010; Little and Collins, 2012).

From this period onwards, an antipathy to taxonomy was almost palpable in some quarters, even if manifested more in neglect than in critique. The typological mentality underlying the enterprise was seen as akin to that of stamp-collecting; it was predicated on a static, almost pre-Darwinian view of biological variation; too much was left to the subjective judgment of the taxonomist; some industrious practitioners had taken 'splitting' to absurd and chaotic extremes; the rules of nomenclature were arcane and obfuscatory. Above all, the work necessary and sufficient to label the entities out there in nature had essentially been done by then. Further fiddling with categories and names was mere finicky detail; and when it led to changes in an approved taxonomic name, that was more a nuisance than a scientific advance.

Since the 1980s or so, however, the tide has been turning, even if taxonomists of some groups (e.g. plants) still fear that their trade is itself an endangered species. Colin Groves must long have been amongst those who sensed that earlier critiques had thrown out both baby and bathwater. In much of his work from the 1960s to the present, he has addressed taxonomic issues both directly (e.g. Groves, 2001a; Groves and Grubb, 2011) and indirectly, through the taxonomic underpinning he has brought to other work (e.g. Groves, 1989; Groves, 2008). I draw on some of his arguments here. 
It says much for the adaptability of Linnaean taxonomy that a pre-evolutionary system for classifying biological diversity should have weathered the intellectual shocks of Darwinism, Mendelian genetics, 1930s population genetics, and in our own time molecular genetics. A further shock came from within taxonomy itself, in the form of a challenge to make taxonomy conform more rigorously to phylogeny. The cladistic school of taxonomy emerged in 1950 with the publication in German of Hennig's major theoretical work; though by 1966, when it appeared in English, other pioneers were already thinking along comparable lines (Cain and Harrison, 1960; Groves, 2001a). Hennig insisted that taxonomic groups should be monophyletic, which many traditional taxonomic groups were not; and he even wanted to have each taxonomic group's rank linked systematically to its antiquity, at least within higher-order taxa. Cladistic taxonomy was indeed a 'bombshell' and initiated a 'scientific revolution' (Groves 2001a: 8, 18).

Since the mid-century 'new synthesis' of evolution with genetics (Huxley, 1942), one particular taxonomic rank - the species - has been a focus of special interest and intensive analysis amongst cladistic and more traditional taxonomists. Why are species special? Part of the answer, as Groves puts it, is that species are 'kinds of animals (and other organisms)' as the lay public generally understands them (2001a: 26). A happy example was provided by Mayr from his fieldwork in the Arfak Mountains of the Vogelkop Peninsula, now in West Papua, Indonesia. He found that local people had 136 vernacular names for the 137 bird species that museum taxonomists recognised as occurring in the area. Their classification conflated just two of the museum taxonomists' species. This, said Mayr, was 'an indication that both groups of observers deal with the same, non-arbitrary discontinuities of nature' (1963: 17). Indeed: the observation vividly illustrates why species are special, and not purely artificial. But Mayr did not claim - nor would Godfrey and Marks (1991) for example, nor Groves - that it provides all the answers to the role of species in evolutionary theory, or solves all the taxonomists' day-to-day practical problems.

So what, then, are species, and why does it matter? The double-barrelled question comes verbatim from Colin Groves himself in recent conversation. But the first part is also the question with which he began a much earlier major theoretical work (Groves, 1989). He has reviewed this long-standing concern several more times, both in detail (Groves, 2001a: Part I) and more succinctly (Groves and Grubb, 2011: 1-10); see also Groves (2001b, 2004, 2012). In this chapter, I start from the solid ground that he established in these reviews (confounding his lament to Mittermeier and Richardson [2008: ii] that 'nobody ever reads Part I' of Primate Taxonomy). Then I shall set off in a quite different direction. 


\section{What are species?}

In introducing the taxonomy of the primates, Groves (2001a) reviewed 11 main concepts of what a species is (amongst sexually reproducing organisms). Importantly, he divided them into two groups: theoretical concepts, dealing with 'what a species is in essence'; and operational concepts dealing with 'how you can recognize one when you meet one' (2001a: 26). Here I only consider one concept from each group.

Mayr's Biological Species Concept (BSC) originated with the neo-Darwinian 'new synthesis', and became part of the prevailing orthodoxy along with it, cited innumerable times now. Under this theoretical concept, species are 'groups of actually or potentially interbreeding natural populations which are reproductively isolated from other such groups' (Mayr, 1963: 19). Reacting against the preceding Typological Species Concept, Mayr and like-minded thinkers were concerned to emphasise species as units of evolution - populations or sets of populations sharing a common gene pool. Reproductive continuity was central under the BSC. Morphology and phenotype played no part in defining species, although Mayr did allow that 'where the taxonomist applies morphological criteria, he uses them as secondary indications of reproductive isolation' (1963: 16-17).

The BSC still fits well with modern evolutionary thinking, and remains important at that level. Groves cited it approvingly in earlier work (e.g. Groves, 1989: 1-3). But his position has become more sceptical (e.g. Groves, 2001a; Groves and Grubb, 2011); and this has much to do with the weaknesses of the BSC as a guide to a working taxonomist. For one thing, if the test is which sets of populations are 'actually or potentially interbreeding' and which are 'reproductively isolated' in nature, that raises visions of the taxonomist as naturalist field-worker, binoculars at the ready, watching interbreeding not happening. Not only is such negative evidence hard to gather and inherently unlikely to convince; often the reality is that the taxonomist works mainly in the museum or the laboratory, on preserved specimens rather than observations in life, providing evidence that bears only inferentially at best on reproductive isolation.

Furthermore, even field observational evidence cannot determine which noninterbreeding populations might potentially interbreed (Groves, 2001a: 26-27; Groves and Grubb, 2011); nor, as Mayr himself rightly insisted (1963: 92), can evidence from captivity settle the question either. The classic, common instance of this problem arises where populations or sets of populations are allopatric. Populations might be separated by geographical barriers or unsuitable habitat, 
so that there is little or no actual interbreeding. But could the separated populations potentially, naturally, interbreed? The BSC provides no clear, evidence-based way of answering that question.

Groves also draws attention to a simpler, more factual problem with the BSC. With extensive genetic evidence from wild populations now available, we can see that good species, recognised by everyone as such, do actually interbreed, at least on occasion. There are both primate and ungulate examples of this (Groves, 2001a; Groves and Grubb, 2011: 2).

Groves concludes that, for all the great merits of Mayr's work, the BSC is irreparably flawed as a basis for practical taxonomy. Even taxonomists professing to implement it have often only paid it lip service, and 'it can be claimed that the BSC had made very little difference in how practicing taxonomists actually practiced' (Groves, 2001a: 27; Groves and Grubb, 2011). One effect that it did have, however, was an ill-effect: a bias arose amongst some workers under the BSC against the recognition of allopatric species, which tended to be 'lumped', even where sympatric species may have been correctly diagnosed (Groves, 2001a: 27).

Amongst the 10 concepts competing to succeed the BSC, Groves' reviews identify a clear winner: the operational Phylogenetic Species Concept (PSC), due principally to Cracraft (e.g. 1983), though further developed by others (Groves, 2001a: 30-32; 2004). Species are seen as evolutionary lineages - units of evolution and biodiversity. The concept is 'based on the results of evolution (on pattern), not on the processes by which these results may or may not have come about' (Groves, 2001a: 31). Cracraft's formal definition of the PSC includes reference to 'patterns of ancestry and descent', a reference which for practical purposes Groves strips out. Like reproductive isolation, it would lead us off towards the untestable. For operational purposes, he defines a species simply as: 'a diagnosable entity' (Groves, 2001a: 32). 'Diagnosable' here means 'identifiable $100 \%$ of the time, having fixed genetic differences from all others' (Groves, 2001a: 313). This is still a demanding definition. Species diagnoses on this basis may admittedly be based on plausible assumptions as to the heritable basis of diagnostic characters (rather than clear demonstrations), and on the indications of small samples as to their prevalence. But at least there is a reasonably objective basis on which to reach a conclusion that can be defended as the best supported one in the current state of knowledge. And it is a concept that is compatible with Hennigian cladistics (Nixon and Wheeler, 1990). Groves does not claim that there are no uncertainties or drawbacks to the PSC; only that they are fewer and less serious than for the competing concepts.

Put in a nutshell, 'the advantage of the PSC is that it depends entirely on the evidence to hand; there is no extrapolation' (Groves and Grubb, 2011: 1). And 'this is as close as we can come to putting a finger on the units of biodiversity. 
The next level ... is where the excitement begins for many workers ... But first we have to determine what the units actually are' (Groves and Grubb, 2011: 2). I agree; and I propose to proceed on that basis.

\section{Why does it matter?}

Does all this make a difference? Indeed it does. It has been precisely the PSC's power to make a real difference to accepted classifications that has made it unwelcome where a high value is placed on taxonomic stability. The difference it can make, simply in terms of the number of species recognised, is illustrated by Cracraft's own work as an avian taxonomist. Cracraft (1992) applied the PSC to the birds of paradise (Paradisaeidae) with dramatic results. A family previously thought to comprise 40-43 species could now boast some 90 of them. The contrast with the taxonomic stability found in the New Guinea example cited earlier - Mayr's from the Arfak Mountains - is instructive. If one's first thought is that perhaps Mayr's finding was simply an outrageous fluke, a second thought, and a third one, show that it is more complex.

While Mayr supplied few details, Bulmer's (1970) ethnotaxonomic research elsewhere in New Guinea provided a case study with more nuance. His work was amongst the Kalam (now the standard spelling, though Bulmer spelt it 'Karam': Pawley, 2011) of the Schrader Mountains. Bulmer estimated that only about $60 \%$ of Kalam terminal taxa for vertebrates correspond well with species as recognised zoologically. This does not, however, conflict with his main argument, that Kalam are like zoologists in being 'concerned with, and to a large extent aware of, the discontinuities which define biological species, even where their folk-taxa do not correspond one-to-one to these' (1970: 1082). The mismatches are explained partly as cases where Kalam are less familiar with those forms, and partly as either Kalam 'lumping' of zoological species (e.g. five microhylid frog species which, unlike all other frogs, they regard as inedible) or Kalam 'splitting' (e.g. where mature male birds of paradise, with their different plumage and behaviour, are placed in a different terminal taxon from females and immature males, even though Kalam know that this is what they are).

The essence of both Mayr's and Bulmer's examples, however, was that they were local. Presumably the species in question were mostly or all sympatric. Cracraft, on the other hand, in surveying a whole radiating family dispersed across the broad New Guinea region, was assessing the taxonomic status of population sets that included many instances of allopatry. What Cracraft had done was not primarily to collect new specimens, and certainly not to find new evidence about reproductive isolation. It was primarily to restore species status to numerous 'operational taxonomic units' (Groves, 2001a: 7), which under 
the BSC had been regarded as subspecies: allopatric, by definition, therefore. 'Restore' because, ironically, many of these taxonomic units had had species status until it became the trend under the BSC to relegate allopatric species to subspecies status where they were similar enough descriptively for that to be plausible. Cracraft's treatment of the evidence was quite traditional, analysing morphological variation in relation to geographical distribution, though his analysis was guided by the criteria of the PSC. The shock was in the outcome. Although Cracraft actually recognised fewer 'terminal taxonomic units' than the 100-115 that had been recognised under the BSC, he more than doubled the number recognised at species, as opposed to subspecies, level. Such a large disturbance of the previously accepted order can make readers uncomfortable. We ourselves are, after all, a classifying species, and sometimes classifications and their anomalies are strongly marked culturally (Douglas, 1966).

The PSC has brought similar, sometimes equally dramatic, changes to mammalian taxonomy. Madagascan primates supply several examples. Louis and others (2006) reviewed the genus Lepilemur (sportive lemurs), a group of 'superficially indistinguishable' (p. 2) primates, and argued on the basis of both molecular and phenotypic data that the true species diversity of the genus was 22 , double that previously recognised. Andriantomphohavana and others (2007) similarly reviewed the taxonomy of the genus Avahi (woolly lemurs), supporting the five species already recognised, and proposing the elevation of two subspecies to species status and the recognition of a further entirely new species. In both genera, the taxa in question are separated by rivers as well as sheer distance: see also this volume (Chapter 15) for a catarrhine case.

A recent and dramatic illustration of the difference that a different species concept can make - and the controversy it can cause - comes from Groves' own work. Groves and Grubb (2011) and Groves and Leslie (2011) have presented a revised scheme for the classification of the ungulates in which, amongst other things, they recognised 279 extant bovid species where only 143 had been recognised previously. This was too much for Zachos and others (2013), who launched a strongly worded critique of authors promoting 'species inflation and taxonomic artefacts'; to which Groves (2013) duly responded.

Their exchange is instructive. The parties are agreed on certain points. Sometimes, traditional classifications do underestimate diversity at the species level. This diversity is worth uncovering and recognising. In this task, genetic data can usefully supplement morphological data. A categorical taxonomic system is not fully adequate to reflecting a continuous evolutionary process, so whether a speciation process is sufficiently advanced to justify formal recognition for an incipient species may sometimes be moot. There can be real-world consequences to recognising more or fewer species. 
But for Zachos et al., the splitting of, for example, one klipspringer species (Oreotragus oreotragus) into 11 species is simply unacceptable: 'spectacular ... taxonomic inflation' (Groves and Grubb, 2011: 275-279; Zachos et al., 2013: 3). Their principal criticisms, across this and other examples, appear to be two: that the PSC has been inappropriately applied; and that there are insufficient data. Despite passing mention of the Genetic Species Concept ('a group of genetically compatible interbreeding natural populations that is genetically isolated from other such groups'), Zachos and others make no clear case as to what species concept or what method of implementing one they would have preferred to see. The very fact of major divergence from tradition in the resulting number of species recognised seems to be a fault perceived in the PSC. As for the data, Groves (2013) concedes the small samples but points out that no more data were available; and he argues that one should draw the conclusion that follows from the available data, while remaining open to testing it against more data once available. Zachos and others make similar criticisms in relation to other examples, e.g. the recognition of six mainland serow (Capricornis) species in place of one (Groves and Grubb, 2011: 255-261; Zachos et al., 2013: 3), even though the data are more abundant in that case. Groves, lacking their trust in traditional species diagnoses, is correspondingly more willing to advance claims based on the PSC.

All these examples - birds of paradise, lemurs, klipspringers and serows concern instances where authors applying the PSC have recognised more species than previously. This does not in itself show that the higher number is either correct or incorrect. Many but not all are taxa previously deemed to be subspecies. All, I believe, are allopatric - often not even parapatric but well separated geographically - with respect to other populations with which they had been or might have been considered conspecific. Allopatry is not invariably central, however, to cases where species diagnosis is affected by subtleties of detail and concept. Among insects and some other invertebrates, sympatric sibling or cryptic species have long been reported, separated reproductively, genetically, ecologically or chronologically (Mayr, 1963). Behaviour and ecology are often important as distinguishing characters, where the morphological differences are slight.

Overall, the species concept deployed not only makes a difference - potentially a large difference - to the classification one comes up with; it is also a difference that matters greatly to taxonomists. To Groves, for one, it matters to make the most scientific, most evidence-based estimate one can of the species-level diversity in nature; and, even if the answer that comes up is unexpected or inconvenient, to take it seriously. But, taxonomists apart, does it matter more widely? 
There is at least one further, and very practical, respect in which it matters. Conservation work risks being misdirected unless it is operating on the best available understanding of the evolutionary lineages it is dealing with. Without that understanding, the rich biodiversity of what survives may be underestimated; but so may the extent and nature of the need for action. The lineages and habitats in direst danger of extinction - or conversely, on a conservation triage approach, those viable enough to benefit from intervention - may not be correctly identified to conservation agencies. Thus, excessive 'lumping' carries an undisputed risk of concealing conservation needs; while Zachos and others add a countervailing concern that excessive 'splitting' may provide additional targets for taxonomically minded trophy hunters and collectors.

In the remainder of this chapter, I shall attempt to explore a quite different practical reason why it is helpful to do as Groves and like-minded scholars have done with the taxa of interest to them: to consider and refine species concepts very carefully and to work from them towards the best attainable empirical determinations and characterisations of species.

\section{Anopheline taxonomy}

Flies of the family Culicidae (Diptera) - mosquitoes - are divided into two subfamilies, Culicinae and Anophelinae; and Anophelinae into three genera, including Anopheles (Krzywinski and Besansky, 2003). By virtue of the blood meals that they imbibe from their hosts - mammal, bird and reptile - the females of many culicid species transmit infections between them, including, in the human case, arboviruses, filariasis and malaria. Because it is only anophelines, specifically Anopheles, of certain species only, that transmit human malaria, there is a disproportionate focus on anophelines in the literature; and they will be my focus too. The number of anopheline species recognised, including cryptic species, has increased substantially in recent years. Below I explore some implications of this development. My debt especially to three recent reviews (Beebe et al., 2013; Sinka et al., 2012; White et al., 2011), which draw on much wider literatures than I shall do directly, will be very apparent.

Anopheles is a very speciose genus, with a near worldwide distribution, containing six subgenera and hundreds of species. Four of the subgenera are endemic to South America, where the genus is likely to have originated, at least 50 million years ago (Reidenbach et al., 2009). Their current distribution includes many regions where malaria does not normally occur endemically nowadays, such as southern Australia and northern Europe - though islands in the Remote Pacific, beyond Buxton's Line which runs east and south of Vanuatu, remain Anopheles-free. In the 1980s, around 400 species of Anopheles were recognised (Bruce-Chwatt, 1985). Now, after much further work in genetics to supplement 
the morphology, 465 species are formally recognised and there are also over 50 unnamed members of species complexes (Sinka et al., 2012). Only a minority of all anopheline species have the capacity to transmit the five malaria parasites that normally infect people (Plasmodium falciparum, P. vivax, P. malariae, $P$. knowlesi and P. ovale), and fewer still do so frequently.

The global distribution of Anopheles species involves complex regionally contrasted patterns of allopatry and sympatry. The southwest Pacific region - lying between Weber's Line in the west (running through the Moluccas) and Buxton's Line in the east, and centred on the islands and archipelagos of New Guinea, the Bismarcks, the Solomons, Vanuatu and Australia - may serve to illustrate this complexity. At best current reckoning, at least 56 Anopheles species occur in this region (Beebe et al., 2013; Foley et al., 2007). Most of these belong to one of five species groups endemic to the Australian Faunal Region (the An. punctulatus, An. longirostris, An. lungae, An. bancroftii and An. annulipes groups). There are also four ungrouped endemic species, and eight species from the Oriental Faunal Region which have dispersed eastwards into the Moluccas or further into the Australian Faunal Region. There are elements of allopatry in their distribution: for example, the An. lungae group occurs only in the Solomons including Bougainville, whereas the $A n$. longirostris and An. bancroftii groups occur only in New Guinea, and the An. annulipes group mainly in Australia though with two representatives in New Guinea. On the other hand, An. farauti (in the An. punctulatus group) occurs throughout the tropical parts of the region, though rarely far from the coast, and is thus sympatric with many other species (Beebe et al., 2013).

The best studied species group in the region is the An. punctulatus group (subgenus Cellia). In the 1980s this group had five recognised member species, of which just three - An. punctulatus, An. koliensis and An. farauti (or An. farauti 1) - were known from Papua New Guinea. Research undertaken around this time was reported in these terms (e.g. Attenborough et al., 1997; Charlwood et al., 1986). Since the 1990s it has become apparent that the situation is more complex. The biodiversity of this species group, and the extent to which it is made up of morphologically similar cryptic species, is only now becoming fully appreciated (Beebe et al., 2013). This is because genetic data have allowed further species-level distinctions to be made where morphological data alone are uninformative or (as it turns out) unreliable. The An. punctulatus group now consists of 13 species. Most of the more recently diagnosed ones were previously included in An. farauti, and some still await a formal name. They have been distinguished via observations on chromosomal inversions, allozyme variation, variation under species-specific genomic DNA probes, and PCR-RFLP variation in ribosomal DNA (rDNA), especially its internal transcribed spacer 2 (ITS2) region. Species status for these taxa was further confirmed in some cases by cross-mating experiments demonstrating sterility, and by lack of hybridity 
at the rDNA locus even in large samples of field-collected specimens. The 13 species appear to be organised as two main clades: most of the An. farauti-like species in one; the An. punctulatus-like species plus An. farauti 4 in the other; with the position of $A n$. koliensis indeterminate (Beebe et al., 2013).

At a broad level, there is much co-occurrence amongst the An. punctulatus group species. Three of the 13 species occur in the Moluccas; four in New Britain; formerly five in the Solomons (including Bougainville), though fewer now; 11 in one or another part of the New Guinea island. In more fine-grained biogeographical terms, there is less true sympatry of these species, especially in New Guinea where different species occupy different regions; and there is also some ecological separation e.g. in breeding habitats. Nonetheless, there is some true sympatry: for example, An. koliensis, An. hinesorum (formerly An. farauti 2) and An. farauti 4 have not only overlapping distributions, especially in New Guinea's inland northern lowlands, but also similar larval habitats, including transient ones created by human and pig activity. They are also not reliably distinguishable on morphological criteria only. The latter two are thus instances of cryptic species-level biodiversity uncovered through genetic research. That they are - unlike the newly recognised vertebrate species discussed earlier sympatric is very interesting. Beebe and others (2013) do not explicitly discuss the species concept that has been applied in diagnosing these and other species in the group; but their methods and findings appear to conform to the PSC.

Similar statements could be made about the other four Anopheles species groups endemic to the region, in which some 25 new species overall have emerged through recent research. These groups are, however, all less well known than the An. punctulatus group.

For a second example, the most thoroughly researched of all, I turn to subSaharan Africa and the An. gambiae species group. For this group we can see research well advanced in some directions that currently still remain in the future for the southwest Pacific anophelines. The major African malaria vector An. gambiae was originally taken to be a single species. Then crossmating experiments showed that sterile male progeny resulted from crossing, first western and eastern coastal saltwater breeding populations with each other or with freshwater breeding populations, and then certain freshwater populations with each other (White et al., 2011). We now have an An. gambiae species complex consisting of some seven well recognised species: the western coastal species An. melas; the eastern coastal species An. merus; a third salttolerant species, An. bwambae, found near hot springs in Uganda; at least two widespread freshwater species, An. gambiae sensu stricto and An. arabiensis, which are extensively but not wholly sympatric; and two allopatric species of more restricted distribution, both originally included in An. quadriannulatus but now separated, again on the strength of crossing experiments, as 
An. quadriannulatus A and B (White et al., 2011) (see also maps of Sinka et al., 2012). Fixed genetic differences between these species were discovered, first karyologically, as banding patterns and paracentric chromosomal inversions, and then at the DNA level, again primarily in the intergenic spacer of rDNA. The species in the An. gambiae complex remain morphologically indistinguishable (White et al., 2011): that is, no morphological differences that are fixed and therefore diagnostic have been identified. Here, then we have a species group smaller than the An. punctulatus one but similarly complex, with at least seven, sometimes sympatric, well studied sibling members clearly recognised as such despite their phenotypic similarity. Species hybrids have been found in the wild and may be fertile if female; but are extremely rare and do not alter the diagnosis of these good species, whose phylogeny and history of ecological interaction with humans are discussed by White and others (2011).

The complexity goes to another level too in this case. A great deal of complexly patterned chromosomal and molecular variation has been discovered within $A n$. gambiae s.s. (hereafter, An. gambiae), and these two modes of variation are not simply related to each other. It transpires that the molecular level is the more fundamental one reproductively. The molecular forms labelled M and S, identified by fixed single-nucleotide differences in rDNA, have been widely considered to be examples of 'incipient speciation', but recently some workers have gone further and accorded them species status, as An. coluzzii and An. gambiae respectively (Coetzee et al., 2013). Though sympatric, they are ecologically differentiated at a micro level, especially in larval habitat. S characteristically breeds in ephemeral rain puddles and its larvae grow fast. $M$ tends to breed in longer-lasting artificial habitats associated with irrigated agriculture; its larvae grow more slowly and are outcompeted by $\mathrm{S}$ in the absence of predators, but are better at predator avoidance - they become more inactive in their presence (White et al., 2011). A recent study in Burkina Faso confirmed strong assortative mating of the forms, whereby: first, most mating swarms were of one form only, temporally or spatially separated from the other; second, even in mixed-form swarms, a large majority of pairs collected were of the same form; and third, even in the tiny number of mixed-form pairs, all the females had sperm of their own form in their spermothecae, not of the males they were caught with, presumably having mated recently with males of their own form (Dabiré et al., 2013). This supports the evidence of Pennetier and others (2010) for close-range mate-type recognition, based specifically on auditory flight-tone matching via difference tones. It also supports their recognition as species. Despite the existence of pre-mating barriers and probably post-mating barriers too, hybridisation of $\mathrm{M}$ and $\mathrm{S}$ does occur, at low but non-negligible and regionally variable levels, and genetic evidence indicates continuing gene flow between forms (White et al., 2011). Most authors prior to Coetzee and others (2013) recognised a strong evolutionary differentiation but did not go beyond calling the forms 'incipient 
species'. As both Groves (2013) and Zachos and others (2013) would presumably agree, in the continuous process whereby species come into existence, there will be instances in which it is moot where we draw any categorical line; and this appears to be one of them. We seem to have an excellent example of speciation under way; and interestingly it is happening sympatrically. The possible future discovery of further complexity and differentiation is not ruled out.

In the two limited examples of anopheline taxonomy chosen for discussion here, then, we can see that, although neither the PSC nor any of its competitor concepts is explicitly invoked, molecular technology and more in-depth research tend to uncover more complexity and greater biodiversity, both unambiguously at the species level and emergent amongst sets of populations, both allopatric and sympatric. Positive and statistically convincing identification of reproductive isolation mechanisms, often by experimentation, has more often been practical with insects than with birds or mammals, but is compatible with the PSC; and the primary criterion of 'fixed genetic differences' (White et al., 2011: 114) captures its essence.

\section{The transmission of malaria}

There are, then, many more anopheline species, and differentiable subpopulations within the formally named species (not always meeting the criteria for subspecies), than were recognised a few years or decades ago. Probably very few concerns have arisen that any anopheline taxa might need conservation. But there is a different practical reason why we should be interested in getting anopheline taxonomy right, and specifically in not underestimating their species biodiversity. That lies in the potential that a better understanding of malaria's vectors should have in combatting the transmission of the Plasmodium parasite. One simple illustration lies in a mistargeted malaria control campaign in Vietnam against a non-vector species misidentified as a vector (Krzywinski and Besansky, 2003; van Bortel et al., 2001). The more fine-grained our knowledge of each species or form, even those that are cryptic, the better guided our interventions should be. As Beebe and others (2013) put it: 'effectiveness of malaria control interventions depends on the biology of the [Anopheles] species present.'

Given the multiplicity of the factors required for human malaria transmission, there are many points at which the cycle might in principle fail or be interrupted. Depending on her proclivities and opportunities, a mosquito's first blood meal might or might not be from a human host; that blood meal might or might not be infected with the gametocytes of one of the plasmodia that cause human malaria; the mosquito might or might not be a competent vector (i.e. susceptible to infection); she might or might not live long enough for the malaria sporozoites to develop and reach her salivary glands; her next blood meal may or, depending 
on similar factors, may not be from another human host, and may or may not start up a new infection in that person; the mosquito may or may not proceed to high levels of reproductive success.

Mosquito survivorship, density and anthropophily are the basis of vectorial capacity, which is thus a matter of numbers and probabilities. Since the proportion of anophelines that have the potential to transmit a malarial infection is typically only a few per cent, quantitative reductions in abundance and biting rates, however these arise, may bring appreciable gains. Current efforts to achieve this amount principally to indoor residual insecticide spraying and (often long-lasting) insecticide-treated bed-nets. Used effectively, these can lead to large reductions in biting rates. A genetic study in Equatorial Guinea has shown large reductions in anopheline populations subject to these measures (Athrey et al., 2012). In addition, larval control measures have, but only lately, been shown to be effective where coverage of larval habitats is high enough (Tusting et al., 2013). And anti-malarial medications, where effective, must reduce the opportunities for mosquitoes to be infected.

The key point here is that the different variables affecting malaria transmission frequently vary in a species-specific way, and sometimes in a populationspecific way. Anopheles species are not all equal in their importance for malaria epidemiology; nor are their roles as malaria vectors simply a function of their global distribution or local abundance. And, as White and others (2011: 112) say, 'the rare species that possess all four of these traits [strong preference for human blood, physiological competence to parasite infection, long life, high population density] are not clustered phylogenetically but rather are interdigitated with nonvector species in four of six subgenera and even in sibling species complexes'. This statement applies globally (Sinka et al., 2012), in Africa (White et al., 2011), and in the Pacific (Beebe et al., 2013). It has long been known that anopheline species vary in their ecology, demography and behaviour as well as their distribution, in ways that affect malaria transmission patterns and the overall importance of each as malaria vectors (Bruce-Chwatt, 1985). But this is true of newly distinguished Anopheles species and populations, too. Important questions now for renewed malaria control or even local elimination efforts include: what are the details of these patterns of variation? And how can malaria transmission interventions best be designed on the basis of that knowledge? I only discuss, selectively, the first question here.

Some 70 Anopheles species, worldwide, out of $\sim 500$, can transmit the Plasmodium parasites; and Sinka and others (2012) designate 41 of those as dominant vector species or species complexes (DVS). In Africa, they designate three species (An. gambiae and An. arabiensis, both in the An. gambiae complex; plus An. funestus) as the most dominant of the continent's DVSs; and a further three species (including two more members of the An. gambiae complex, An. melas 
and An. merus) and one species complex as secondary DVSs. The recognition by some authors of An. coluzzii (see above) brings the list of most dominant DVSs to four.

Of the 56 species in the Pacific region, Beebe and others (2013) divide the 38 which occur in New Guinea, the Bismarcks, the Solomons and/or Vanuatu into four vector status categories: 3 primary vectors (all in the An. punctulatus group); 18 secondary vectors (including 4 in the An. punctulatus group); 8 possible vectors (including 1 in the An. punctulatus group), pending more extensive research; and 9 non-vectors (including 5 in the An. punctulatus group).

The three primary Pacific vectors of malaria go by the names longest-known in the An. punctulatus group: An. farauti s.s., An. koliensis and An. punctulatus itself. All are widespread in the region and can be locally abundant. Some key features of their species-specific distribution, ecology and behaviour, relevant to their vectorial capacity, are summarised in broad terms in Table 7.1.

Table 7.1: Key features of the primary Pacific malaria vectors.

\begin{tabular}{|c|c|c|c|c|c|}
\hline Species & Distribution & Environment & Breeding sites & Longevity & Anthropophily \\
\hline An. farauti & $\begin{array}{l}\text { Moluccas } \\
\text { New Guinea } \\
\text { Bismarcks } \\
\text { Solomons } \\
\text { Vanuatu } \\
\text { N. Australia }\end{array}$ & $\begin{array}{l}\text { Seldom far } \\
\text { from coasts }\end{array}$ & $\begin{array}{l}\text { Small ground } \\
\text { pools to } \\
\text { large coastal } \\
\text { swamps \& } \\
\text { lagoons. } \\
\text { Larvae tolerate } \\
\text { brackish water }\end{array}$ & Variable & $\begin{array}{l}\text { Adaptable } \\
\& \text { variable: } \\
\text { readily feeds } \\
\text { on humans } \\
\text { but in many } \\
\text { places also } \\
\text { pigs, dogs } \\
\& \text { probably } \\
\text { native birds \& } \\
\text { mammals; in } \\
\text { the Solomons } \\
\text { strongly } \\
\text { anthropophilic }\end{array}$ \\
\hline An. koliensis & $\begin{array}{l}\text { New Guinea } \\
\text { New Britain } \\
\text { Buka } \\
\text { Formerly } \\
\text { most of } \\
\text { Solomons }\end{array}$ & $\begin{array}{l}\text { Inland } \\
\text { lowlands \& } \\
\text { river flood } \\
\text { plains to } \\
300 \mathrm{~m} \text { a.s.l. }\end{array}$ & $\begin{array}{l}\text { Wheel tracks, } \\
\text { drains, natural } \\
\text { pools, swamps }\end{array}$ & Medium & $\begin{array}{l}\text { Prefers } \\
\text { humans; will } \\
\text { feed on pigs \& } \\
\text { dogs }\end{array}$ \\
\hline $\begin{array}{l}\text { An. } \\
\text { punctulatus }\end{array}$ & $\begin{array}{l}\text { Moluccas } \\
\text { New Guinea } \\
\text { Bismarcks } \\
\text { Buka } \\
\text { Formerly } \\
\text { Solomons }\end{array}$ & $\begin{array}{l}\text { Lowlands, } \\
\text { foothills, } \\
\text { mountain } \\
\text { valleys. } \\
\text { Clay soils, } \\
\text { perennial } \\
\text { rainfall }\end{array}$ & $\begin{array}{l}\text { Rock pools in } \\
\& \text { near rivers } \\
\& \text { streams, } \\
\text { wheel ruts, } \\
\text { foot \& hoof } \\
\text { prints, pig } \\
\text { wallows, } \\
\text { transient } \\
\text { water. Eggs } \\
\text { can survive } \\
\text { desiccation }\end{array}$ & $\begin{array}{l}\text { Most } \\
\text { long lived } \\
\text { of its } \\
\text { species } \\
\text { group }\end{array}$ & $\begin{array}{l}\text { Most } \\
\text { anthropophilic } \\
\text { of its species } \\
\text { group }\end{array}$ \\
\hline
\end{tabular}


Relative to the primary vectors, other species play smaller roles, or no role, in malaria transmission, for reasons generally related to the criteria set out by White and others (2011). At the extreme, several New Guinea species including An. farauti 5 are rare, An. clowi so rare that it has only been found twice since 1946; An. rennellensis only occurs on Rennell Island (Solomons) where there is little or no malaria transmission; the three members of the An. lungae complex (endemic to Solomons) bite humans but have never been found infected with human malaria parasites, and at least one of them is short-lived, so their capacity to transmit malaria is unconfirmed; An. irenicus (formerly An. farauti 7) is not only restricted to Guadalcanal (Solomons) but also has never been recorded as biting humans, despite local abundance as indicated by larval collections. Thus these species and some others play nil, negligible or unproven roles in malaria transmission (Beebe et al., 2013).

This leaves, however, a number of secondary vectors, including newly recognised species, which may play significant malaria transmission roles on top of those of the primary vectors, at least locally where they occur or are abundant. Within the An. punctulatus group, for instance, An. farauti 6 is quite common in the cool moist highlands valleys of New Guinea over $1000 \mathrm{~m}$ a.s.l., to which it appears adapted; and it probably plays a major role in the now worsening problem of highlands malaria transmission. An. farauti 4, An. hinesorum (formerly An. farauti 2) and An. koliensis all transmit malaria, but are hard to distinguish morphologically, and are all sympatric in lowland New Guinea; so more field research is still required to characterise sharply the abundance, ecology and vectorial properties of the first two especially. An. hinesorum in New Guinea readily bites humans but is highly zoophilic in Buka, Bougainville and the Solomons. Similarly, mosquitoes of the An. longirostris complex transmit malaria but have been found to be zoophilic in some areas and anthropophilic in others; whether reflecting species-specific behavioural differences between the cryptic species in this complex remains to be seen following further research (Beebe et al., 2013).

As with taxonomy, so also with vectorial capacity, more research has been undertaken in Africa than in the Pacific. Within the morphologically homogeneous An. gambiae complex, An. gambiae is usually considered the most anthropophilic, though there are grounds to see the situation as more complex. An. gambiae thrives in many different environments, but appears specialised in its association with humans in all those environments and at all stages of its life cycle (White et al., 2011). Ayala and Coluzzi (2005) argue that An.gambiae is a very young species (or, now, species pair), descended from an An. quadriannulatuslike ancestor; and thence ultimately, like other complex members, from an An. arabiensis-like ancestor. The proposed selection pressures were principally those produced by human population density and environmental impacts, beginning in the African late Neolithic, less than 4,000 years ago; resulting, for 
example, in heliophilic larvae. Along with its anthropophily, An. gambiae is also endophagic and endophilic, with implications for intervention (White et al., 2011). The highly anthropophilic incipient species M and S, or An. coluzzii and An. gambiae, show a partial but marked ecological differentiation as described above, with $\mathrm{M}$ predominant in more urbanised, more polluted environments with longer-lasting, more predator-infested breeding habitats; whereas S predominates in more rural settings (Kamdem et al., 2012).

Where sympatric, An. gambiae and An. arabiensis compete, with An. gambiae prevailing in rainforests and other relatively well watered habitats, and An. arabiensis in drier ones. An. arabiensis possibly dispersed from the Middle East over 6,000 years ago, probably as a zoophilic and exophilic species, acquiring anthropophily secondarily, and being now second in that respect only to An. gambiae in East Africa - though it remains zoophilic and exophilic in Madagascar, perhaps on account of historically lower population density (Ayala and Coluzzi, 2005).

At the opposite extreme of anthropophily, still within the same superficially homogeneous species complex, An. quadriannulatus is generally reported to be highly zoophilic and therefore a non-vector of human malaria. It has never been found naturally infected with Plasmodium falciparum malaria, though it has been shown in the laboratory to be a competent vector of it (White et al., 2011).

Another pressure driving the recent and rapid radiation of the An. gambiae complex has apparently been the adaptation permitting larval physiological tolerance of brackish water - twice independently, with one lineage, more closely related to An. quadriannulatus, leading to An. bwambae and the western coastal species An. melas, and the other, more closely related to An. gambiae, leading to the eastern coastal species $A n$. merus. This adaptation would appear to be the dominant differentiating factor for these species, given their still saltwater-focused distribution (Ayala and Coluzzi, 2005).

Anopheline mosquitoes' role as malaria vectors brings them no known evolutionary advantage. That there are variations amongst species, populations and individual mosquitoes in genes conferring immune resistance to malarial infection might suggest that there is some evolutionary cost. Laboratory genetic lines of An. gambiae more refractory to infection are able to kill many immature Plasmodium parasites - though $P$. falciparum least, and African P. falciparum least of all. These findings may not be transferable to field-collected mosquitoes, whose median parasite density is typically very low. But if they are transferable, an evolutionary 'arms race' might be hypothesised, whereby An. gambiae has evolved a degree of resistance to infection with the Plasmodium species and strains that naturally infect it, but in turn those plasmodia most exposed to this selection pressure have evolved the ability to evade the mosquitoes' immune 
defences. White and others (2011) review the now substantial evidence now available on immune gene variation affecting their vector competence. The net result is great variation, even within malaria-endemic zones, between and within species, in the likelihood that an individual mosquito's bite will be infective.

The processes that direct that individual mosquito's bite to a human host, rather than some other vertebrate (for which it may not be infective), are also crucial epidemiologically; and they vary according partly to anopheline species or population. As a variable, however, anthropophily can be problematic. Mosquito preferences for particular host species do not necessarily translate directly into biting rates on those species, as hosts may differ in their numbers, accessibility, presence in particular micro-environments, and defensive behaviour. Thus true host preferences unbiased by these factors are generally unmeasurable in uncontrolled field conditions. Consequently, descriptions such as anthropophilic or zoophilic are frequently based on less than satisfactory evidence. Nonetheless, it is clear that anophelines do have preferences amongst hosts, that these preferences vary between species, and that they play a part in explaining the different biting rate patterns of different species: indeed population differences within An. gambiae have been demonstrated (Lefèvre et al., 2009). Of the multiple cues thought to guide mosquitoes' activation, anemotaxis, close-range approach to hosts, and landing behaviour, some are non-specific (warmth, humidity, carbon dioxide); but others are species-specific - human or cattle odours, for example, eliciting different responses according to the anthropophily/zoophily of the anopheline species. Amongst anthropophilic species there is also differential attraction to different individual humans, and one factor which exacerbates this in An. gambiae - one further risk factor for malaria, in other words - is beer consumption (Lefèvre et al., 2010).

Field estimates of population density are generally derived from mosquito landing rates at human, animal or artificial baits, and are therefore subject to the extent of their attraction to those baits. The abundance of more zoophilic mosquitoes is likely to be underestimated in situations where most of the data come from human landing rates. Nonetheless, despite biases affecting the estimates, species differences in population density are clearly real and sometimes very large.

An illustrative picture of some more recently diagnosed anopheline species, reviewed in relation to White and others' (2011) four criteria for vectorial efficiency, is presented in Table 7.2. As this table shows, there are potentially major malariological implications to making taxonomic distinctions amongst anophelines, including between species previously not distinguished. 
Taxonomic Tapestries

Table 7.2: Selected contrasts in variables relevant to malaria transmission between selected cryptic species in the An. punctulatus and An. gambiae species complexes.

\begin{tabular}{|c|c|c|c|c|c|}
\hline $\begin{array}{l}\text { Species } \\
\text { complex }\end{array}$ & Species & $\begin{array}{l}\text { Anthropophily/ } \\
\text { zoophily* }\end{array}$ & $\begin{array}{l}\text { Estimated } \\
\text { population } \\
\text { density* }\end{array}$ & Longevity & $\begin{array}{l}\text { Vector } \\
\text { competence }\end{array}$ \\
\hline \multirow{4}{*}{$\begin{array}{l}\text { An. } \\
\text { punctulatus } \\
\text { (Pacific) }\end{array}$} & punctulatus & $\begin{array}{l}\text { Most } \\
\text { anthropophilic } \\
\text { in complex but } \\
\text { ranges from } \\
\text { total to modest } \\
\text { dependence on } \\
\text { human blood }\end{array}$ & High & Long-lived & Yes \\
\hline & farauti & Highly variable & High & Variable & Yes \\
\hline & hinesorum & $\begin{array}{l}\text { Variable } \\
\text { geographically }\end{array}$ & $\begin{array}{l}\text { Variable } \\
\text { geographically }\end{array}$ & & Yes \\
\hline & irenicus & Highly zoophilic & $\begin{array}{l}\text { Common } \\
\text { locally }\end{array}$ & & No? \\
\hline \multirow{3}{*}{$\begin{array}{l}\text { An. } \\
\text { gambiae } \\
\text { (Africa) }\end{array}$} & gambiae & $\begin{array}{l}\text { Highly } \\
\text { anthropophilic }\end{array}$ & High & & Yes \\
\hline & arabiensis & $\begin{array}{l}\text { Second most } \\
\text { anthropophilic }\end{array}$ & High & & Yes \\
\hline & quadriannulatus & Highly zoophilic & & & $\begin{array}{l}\text { Shown in } \\
\text { lab only }\end{array}$ \\
\hline
\end{tabular}

Note: *See text for discussion of difficulties in making unbiased estimates of these variables.

Source: Summarised from Beebe and others (2013); White and others (2011).

Research on anopheline demography, ecology and behaviour clearly has important potential implications - not pursued here - for interrupting malaria transmission. Suffice it to say that, to the (substantial) extent that these characteristics vary along taxonomic lines, especially species-specific lines, a fine-grained taxonomy of anophelines too has an important role in fresh approaches in the field to the still huge problem of malaria. The recent recognition of An. coluzzii as a species distinct from An. gambiae only strengthens this point.

To counterbalance optimism with a necessary caution, it also needs to be noted that we also have evidence for: phenotypic adaptability according to circumstances; variation within currently recognised species and even incipient species due either to such adaptability or genetic differentiation of subpopulations; and rapid changes in these traits due to either evolutionary or behavioural change. 


\section{Conclusion}

The circle that I have attempted to square in this piece has been to seek a perspective, from my own angle as a biological anthropologist interested above all in one particular species (ourselves), on a central interest of Colin Groves: that is, on species concepts, species diagnosis, species biodiversity, and indeed the origin of species. My approach has been to review, first, species concepts, and thence, selected recent developments in the taxonomy of Anopheles, the mosquito genus that, by transmitting malaria, still wreaks enormous havoc upon human life and health. This review supports the proposition that a fine-grained taxonomy, based on the PSC criterion of fixed inherited differences, and including recognition of cryptic and incipient species that are barely distinguishable or indistinguishable morphologically, is an important prerequisite of further fundamental biological research on these mosquito populations. Optimum practical intervention also depends upon it: in this case, not in a conservation context but to improve human health in the tropical Western Pacific, subSaharan Africa and other places still greatly afflicted by this scourge.

\section{Acknowledgements}

This piece is written out of my appreciation of an almost career-long collaboration with the acute, polymathic, formidably industrious, frequently humorous, ever equable Colin Groves, my closest colleague in the School of Archaeology and Anthropology at The Australian National University. To Tom Burkot of James Cook University, I owe not only my long-ago introduction to malarial entomology but also my extreme gratitude for valuable guidance before this piece was written and a critical reading of it afterwards. Nigel Beebe of the University of Queensland and Nora Besansky of the University of Notre Dame were also most helpful entomologically. Andrew Pawley of ANU drew my attention to a most useful reference. Any remaining errors are of course my own responsibility. I thank the volume editors, Alison Behie and Marc Oxenham of ANU, for their advice and forbearance.

\section{References}

Andriantomphohavana R, Lei R, Zaonarivelo JR, Engberg SE, Nalanirina G, McGuire SM, Shore GD, Andrianasolo J, Herrington K, Brenneman RA et al. 2007. Molecular phylogeny and taxonomic revision of the woolly lemurs, genus Avahi (Primates: Lemuriformes). Lubbock, TX: Museum of Texas Tech University. 
Athrey G, Hodges TK, Reddy MR, Overgard HJ, Matias A, Ridl FC, Kleinschmidt I, Caccone A, Slotman MA. 2012. The effective population size of malaria mosquitoes: Large impact of vector control. PLoS Genetics 8(12):e1003097.

Attenborough RD, Burkot TR, Gardner DS. 1997. Altitude and the risk of bites from mosquitoes infected with malaria and filariasis among the Mianmin people of Papua New Guinea. Trans R Soc Trop Med Hyg 91:8-10.

Ayala FJ, Coluzzi M. 2005. Chromosome speciation: Humans, Drosophila, and mosquitoes. Proc Natl Acad Sci U S A 102(Suppl 1):6535-6542.

Beebe NW, Russell TL, Burkot TR, Lobo NF, Cooper RD. 2013. The systematics and bionomics of malaria vectors in the southwest Pacific. In: Manguin S, editor. Anopheles mosquitoes: New insights into malaria vectors. New York: Intech Publishing.

Bruce-Chwatt LJ. 1985. Essential Malariology. London: William Heinemann Medical Books.

Bulmer R. 1970. Which came first, the chicken or the egg-head? In: Pouillon J, Maranda P, editors. Échanges et Communications: Mélanges offerts à Claude Lévi-Strauss à L'Occasion de son 60ème Anniversaire. The Hague: Mouton.

Cain AJ, Harrison GA. 1960. Phyletic weighting. Proc Zool Soc Lond 135(1):1-31.

Charlwood JD, Graves PM, Alpers MP. 1986. The ecology of the Anopheles punctulatus group of mosquitoes from Papua New Guinea: A review of recent work. P N G Med J 29(1):19-26.

Coetzee M, Hunt RH, Wilkerson RC, della Torre A, Coulibaly MB, Besansky NJ. 2013. Anopheles coluzzii and Anopheles amharicus, new members of the Anopheles gambiae complex. Zootaxa 3619(3):246-274.

Cracraft J. 1983. Species concepts and speciation analysis. In: Johnston RF, editor. Current Ornithology. New York: Plenum Press. pp. 159-187.

Cracraft J. 1992. The species of the birds-of-paradise (Paradisaeidae): Applying the phylogenetic species concept to a complex pattern of diversification. Cladistics 8:1-43.

Dabiré KR, Sawadodgo S, Diabate A, Toe KH, Kengne P, Ouari A, Costantini C, Gouagna C, Simard F, Baldet T et al. 2013. Assortative mating in mixed swarms of the mosquito Anopheles gambiae s.s. M and S forms, in Burkina Faso, West Africa. Med Vet Entomol 27:298-312. 10.1111/mve.2013.27. issue-3. 
Douglas M. 1966. Purity and danger: An analysis of concepts of pollution and taboo. London: Routledge \& Kegan Paul.

Foley DH, Wilkerson RC, Cooper RD, Volovsek ME, Bryan JH. 2007. A molecular phylogeny of Anopheles annulipes (Diptera: Culicidae) sensu lato: The most species-rich anopheline complex. Mol Phylogenet Evol 43(1):283-297.

Fuentes A. 2010. The new biological anthropology: Bringing Washburn's New Physical Anthropology into 2010 and beyond - the 2008 AAPA luncheon lecture. Yearb Phys Anthropol 53:2-12.

Godfrey L, Marks J. 1991. The nature and origins of primate species. Yearb Phys Anthropol 34:39-68.

Groves CP. 1989. A theory of human and primate evolution. Oxford: Clarendon Press.

Groves CP. 2001a. Primate taxonomy. Washington, DC: Smithsonian Institution Press.

Groves CP. 2001 b. Why taxonomic stability is a bad idea, or why are there so few species of primates (or are there?). Evol Anthropol 10:192-198.

Groves CP. 2004. The what, why, and how of primate taxonomy. Int J Primatol 25:1105-1126.

Groves CP. 2008. Extended family: Long-lost cousins. A personal look at the history of Primatology. Arlington, VA: Conservation International.

Groves CP. 2012. Species concept in primates. Am J Primatol 74:687-691.

Groves CP. 2013. The nature of species: A rejoinder to Zachos et al. Mamm Biol 78(1):7-9.

Groves CP, Grubb P. 2011. Ungulate taxonomy. Baltimore: Johns Hopkins University Press.

Groves CP, Leslie DM. 2011. Family Bovidae (Hollow-horned ruminants). In: Wilson DE, Mittermeier RA, editors. Handbook of the mammals of the world. Barcelona: Lynx Edicions.

Huxley JS. 1942. Evolution: The modern synthesis. London: Allen \& Unwin.

Kamdem C, Tene Fossog B, Simard F, Etouna J, Ndo C, Kengne P, Boussès P, Etoa F-X, Awono-Nkondjio C, Besansky NJ et al. 2012. Anthropogenic habitat disturbance and ecological divergence between incipient species of the malaria mosquito Anopheles gambiae. PLoS ONE 7(6):e39453. 
Taxonomic Tapestries

Krzywinski J, Besansky NJ. 2003. Molecular systematics of Anopheles: From subgenera to subpopulations. Annu Rev Entomol 48:111-139.

Lefèvre T, Gouagna L-C, Dabiré KR, Elguero E, Fontenille D, Costantini C, Thomas F. 2009. Evolutionary lability of odour-mediated host preference by the malaria vector Anopheles gambiae. Trop Med Int Health 14(2):228-236.

Lefèvre T, Gouagna L-C, Dabiré KR, Elguero E, Fontenille D, Renaud F, Costantini C, Thomas F. 2010. Beer consumption increases human attractiveness to malaria mosquitoes. PLOS ONE 5(3):e9546.

Little MA, Collins KJ. 2012. Joseph S. Weiner and the foundation of post-WWII human biology in the United Kingdom. Yearb Phys Anthropol 55:114-131.

Louis EE, Engberg SE, Lei R, Geng H, Sommer JA, Andriantomphohavana R, Randria G, Prosper, Ramaromilanto B, Rakotoarisoa G et al. 2006. Molecular and morphological analyses of the Sportive Lemurs (family Megaladapidae: genus Lepilemur) reveals 11 previously unrecognized species. Special Publications. Lubbock, TX: Museum of Texas Tech University.

Mayr E. 1963. Animal species and evolution. Cambridge, Mass: Belknap Press of Harvard University Press.

Mittermeier RA, Richardson M. 2008. Foreword. In: Groves CP, Extended family: Long-lost cousins. A personal look at the history of Primatology. Arlington, VA: Conservation International.

Nixon KC, Wheeler QD. 1990. An amplification of the phylogenetic species concept. Cladistics 6:211-223.

Pawley A. 2011. A dictionary of Kalam with ethnographic notes. Canberra: Pacific Linguistics.

Pennetier C, Warren B, Dabiré KR, Russell IJ, Gibson G. 2010. 'Singing on the wing' as a mechanism for species recognition in the malarial mosquito Anopheles gambiae. Curr Biol 20:131-136.

Reidenbach KR, Cook S, Bertone MA, Harbach RE, Wiegmann BM, Besansky NJ. 2009. Phylogenetic analysis and temporal diversification of mosquitoes (Diptera: Culicidae) based on nuclear genes and morphology. BMC Evol Biol 9:298.

Sinka ME, Bangs MJ, Manguin S, Rubio-Palis Y, Chareonviriyaphap T, Coetzee M, Mbogo CM, Hemingway J, Patil AP, Temperley WH et al. 2012. A global map of dominant malaria vectors. Parasit Vectors 5(69):1-11. 
Tusting LS, Thwing J, Sinclair D, Fillinger U, Gimnig J, Bonner KE, Bottomley C, Lindsay SW. 2013. Mosquito larval source management for controlling malaria. Cochrane Database of Syst Rev 2013(8).

van Bortel, W, Harbach, RE, Trung HD, Roelants, P, Backeljau, T, Coosemans M. 2001. Confirmation of Anopheles varuna in Vietnam, previously misidentified and mistargeted as the malaria vector Anopheles minimus. Am J Trop Med Hyg 65(6):729-732.

Washburn SL. 1951. The new physical anthropology. Trans N Y Acad Sci 13(7):298-304.

White BJ, Collins FH, Besansky NJ. 2011. Evolution of Anopheles gambiae in relation to humans and malaria. Annu Rev Ecol Evol Syst 42:111-132.

Zachos FE, Apollonio M, Barmann EV, Festa-Bianchet M, Golich U, Habel JC, Haring E, Kruckenhauser L, Lovari S, McDevitt AD, Pertoldi C, Rossner GE, Sanchez-Villagra MR, Scandura M, Suchentrunk F. 2013. Species inflation and taxonomic artefacts - a critical comment on recent trends in mammalian classification. Mammalian Biology 78:1-6. 
This text is taken from Taxonomic Tapestries: The Threads of Evolutionary, Behavioural and Conservation Research, edited by Alison M Behie and Marc F Oxenham, published 2015 by ANU Press, The Australian National University, Canberra, Australia. 